\title{
Exploration of Pertinent Apparel Production Systems for Bangladeshi Clothing Industries
}

\author{
Nasrin Ferdous, Reashad Bin Kabir \\ Department of Apparel Manufacturing Management \& Technology, Shanto-Mariam University of Creative Technology, Dhaka, Bangladesh
}

Email address:

nasrinferdous@gmail.com (N. Ferdous),robinreashad@yahoo.com (R. B. Kabir)

To cite this article:

Nasrin Ferdous, Reashad Bin Kabir. Exploration of Pertinent Apparel Production Systems for Bangladeshi Clothing Industries. International Journal of Science, Technology and Society. Vol. 3, No. 4, 2015, pp. 220-224. doi: 10.11648/j.ijsts.20150304.27

\begin{abstract}
Like most industries that adopt a reactive manufacturing strategy, the clothing industry changes only when external forces dictate that the current approach or strategy will no longer satisfy the prevailing business environment. This paper presents the Apparel Manufacturing Systems and discusses the underlying premises that support the success of Apparel Production Systems both in the formative stages and during sustained operation. A review of the known origins of manufacturing processes illustrate how the production system can be used to advantage for clothing manufacture. No single solution fits all products/tasks in fully optimizing Socio technical System (STS), given different technologies, environment and people, etc. An attempt was made in this paper to show the handy uses of diverse production system in Bangladeshi Garments Industries.
\end{abstract}

Keywords: Clothing Industry (CLI), Production (PRN), Manufacturing (MAN), Production Management System (PMS), Product Line (PRL)

\section{Introduction}

An apparel Production system is an integration of materials handling, production processes, personnel, and equipment that directs workflow and generates finished products. Three types of production systems commonly used to produce apparel are progressive bundle, unit Production, and modular production. Each system requires an appropriate management philosophy, materials handling methods, floor layout, and employee training. Firms may combine or adapt these systems to meet their specific production needs. Firms may use only one systems a combination of systems for one product line, or different systems for different product lines in the same plant [1].

Since the mid-1970s, Apparel Manufacturers and other Apparel companies that contract for the production of apparel, have searched for strategies suitable to capture the increasingly elusive apparel customer while searching for ways to cut costs and deliver more product variety at a faster pace $[2,3,4]$. During these decades, low-cost labor from a number of global sources was a lure that drew U.S. apparel companies to use off-shore manufacturing facilities however the Rising costs of fuel for transportation and the demand for higher wages in many countries are causing apparel industries to re-examine their current off-shore strategies [5, 6].

As apparel companies consider a return to domestic production, they will be making a choice in production facilities, including production systems. These companies must hire or acquire production systems that will accommodate variations in style changes, shorter lead times and smaller size, in other words, companies need production system that will provide flexibility, speed and cost reductions. Selection of the right production system is considered critical to market success $[5,7,8]$.

The ever improving living standards and rapidly changing fashion trends are pushing apparel manufacturers to respond as fast as possible to model and quantity changes and to produce high-quality, low-cost products. Given this challenge, new production systems were adopted and experimented in the apparel industries [9].

\section{Literature Review}

\subsection{Classification Production System}

Production System can be classified in different ways. A 
number of writers and experts segmented this in different ways. They are as follows:

Types of production system based on order quantity

a. Individual Production: It is also known as making through. It is the traditional method in which entire garment is assembled by one operator. Each product is made only once or in very small quantities. This system requires highly experienced operators and versatile machines.

b. Batch Production: It is used for larger, though fixed quantities of large identical articles either for stock or to order.

c. Mass Production: In this production, large quantities of identical products are made continuously [10].

Types of production system based on customer or consumer nature

a. Bespoke Production: This type of production is on behalf of individual clients, according to individual size and requirements.

b. Industrial Production: Production is geared to an anonymous, statistically and/ or demographically and culturally defined target consumer group [11].

\subsection{Commonly Used Production Systems in Bangladeshi Apparel Industries}

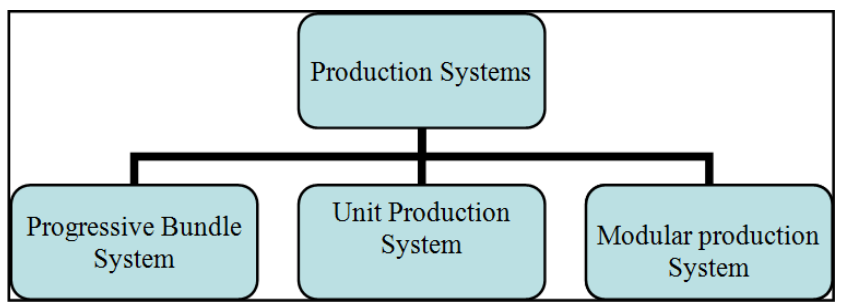

Figure 1. Commonly used to Production Systems in Apparel Industries.

Progressive bundle system (PBS)

The progressive bundle system (PBS) gets its name from the bundles of garment parts that are moved sequentially from operation to operation, This system often referred to as the traditional production system has been widely used by apparel manufacturers for several decades and sill in use today. The Technical Advisory Committee of AA.MA (1993) reports that $80 \%$ of apparel manufacturers used the bundle system. The committee also predicts that use of bundle system would decrease as firms seek more flexibility in their production systems.

Bundles consist of garment parts needed to complete a specific operation or garment component. For example, an operation bundle for pocket setting might include shirtfronts and pockets that are to be attached. Bundle sizes may range from 2 to 100 parts. Some firms operate with a standard bundle size, while other firms vary bundle sizes according to cutting orders, fabric shading, size of the pieces in the bundle, and the operation that is to be completed. Some firms use a dozen or multiples of a dozen because their sales are in dozens.

Bundles are assembled in the cutting room where cut parts are matched up with corresponding parts and bundle tickets.
Bundle tickets consist of a master list of operations and corresponding coupons for each operation. Each bundle receives a ticket that identifies the style number, size, shade number, list of operations for routing, and the piece rate for each operation. Operators retain a corresponding segment of the bundle coupon for each bundle they complete. At the end of the workday, bundle coupons are turned in, and the earned time from completed bundle tickets is totaled to determine the operator's compensation. Firms may use electronic bundle tickets or smart cards that accompany each bundle and that are swiped at each workstation along with identification cards. This reduces paper-work, facilitates access to information, and eliminates lost bundle tickets.

Bundles of cut parts are transported to the sewing room and are given to the operator scheduled to complete the operation. One operator is expected to per- form the same operation on all the pieces in the bundle, to retie the bundle, to process the coupon, and to set it aside until it is picked up and moved to the next operation. A progressive bundle system may require a high volume of work in process because of the number of units in the bundles and the large buffer of backup work that is needed to ensure a continuous workflow for all operators (Figure 2). The firm's materials handling system facilitates bundle movement between operations [1].

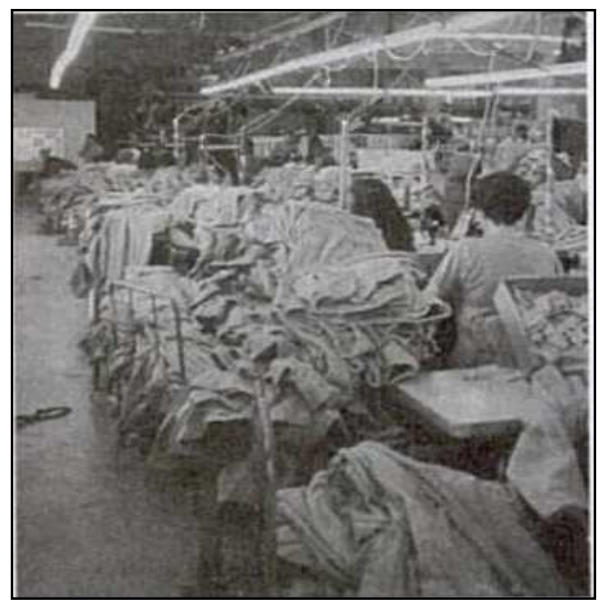

$\mathrm{A}[12]$

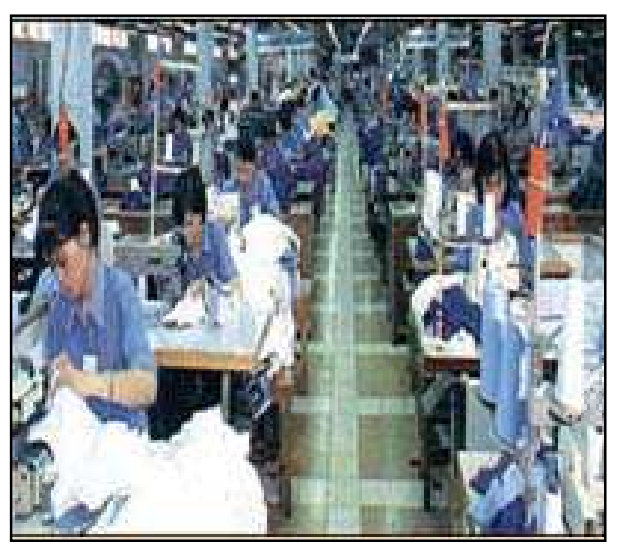

$\mathrm{B}[13]$

Figure 2. Progressive Bundle System. 
However, the progressive bundle system may be used with a skill center or line layout depending on the order that bundles are advanced through production. Each style may have different processing requirements and thus different routing. Routing identifies the basic operations, sequence of production, and the work centers where those operations are to be performed, some operations are common to many styles and at those operations, and work may build up waiting to be processed.

The progressive bundle system is driven by costefficiency for individual operations. Operators perform the same operation on a continuing basis, which allows them to increase their speed and productivity. Operators who are compensated by piece rates become extremely efficient at one operation and may not be willing to learn a new operation because it reduces their efficiency and earnings. Individual operators that work in a progressive bundle system are independent of other operators and the final product.

Slow processing, absenteeism, and equipment failure may also cause major bottlenecks within the system. Large quantities of work in process are often characteristic of this type of production system. This may lead to longer throughput time, poor quality concealed within bundles, large inventory, extra handling, and difficulty in controlling inventory

The success of a bundle system may depend on how the system is set up and used in a plant. This system may allow better utilization of specialized machines, because output from one special-purpose automated machine may be able to supply several operators for the next operation. Small bundles allow faster throughput unless there are bottlenecks and extensive waiting between operations. [11]

Positive sides of progressive bundle system:

- This system may allow better utilization of specialized machines, as output from one special purpose automated ma-chine may be able to supply several operators for the next operation.

- Small bundles allow faster throughput unless there are bottlenecks and extensive waiting between operations.

- Weakness of progressive bundle system:

- Slow processing, absenteeism, and equipment failure may also cause major bottlenecks within the system

- Large quantities of work in process. This may lead to longer throughput time, poor quality concealed by bundles

- Large inventory, extra handling and difficulty in controlling inventory. [14]

Unit production system (UPS)

As a mechanical system this has been in use for many years, but a major advance was made in 1983 when computers were first used to plan, control and direct the flow of work through the system.

The operational principles are as follows:
All the components for one garment are loaded into a carrier at a workstation specially designed for this purpose. The carrier itself is divided into sections, with each section having a quick-release clamp, which prevents the components from falling out during movement through the system. When a batch of garments has been loaded into carriers they are fed past a mechanical or electronic device, which records the number of the carrier and addresses it to its first destination. Some of the more intelligent systems address the carriers with all the destinations they will have to pass through to completion.

The loaded carriers are then fed onto the main powered line, which continually circulates between the rows of machines. This main, or head, line is connected to each workstation by junctions, which open automatically if the work on a carrier is addressed to that particular station. The carrier is directed to the left side of the operator and waits its turn along with the other carriers in the station.

When the operator has completed work on one carrier, a push button at the side of the sewing machine is pressed and this actuates a mechanism, which transports the carrier back to the main line. As one carrier leaves the station, another is automatically fed in to take its place. When the carrier leaves the station it is recorded on the data collection system, and then addressed to its next destination.

Unit Production System requires substantial investments, which are not always justified by conventional payback calculations. Apart from the measurable tangible benefits, UPS also have many intangible benefits such as a more orderly and controlled flow of work, and the ability via the control computer of simulating the production situation some time in advance. These intangibles are difficult to measure, but in themselves make a very positive contribution to the overall viability of the unit.

Overall, unit production systems have major advantages over the other entire manual and the mechanical systems used for the mass production of clothing. Most importantly, they provide a clothing factory with the capability to respond quickly to any changes, which might occur. In the fast moving fashion business, this is essential.

Positive sides of unit production system:

- Bundle handling completely eliminated.

- The time involved in the pick-up and disposal is reduced to minimum.

- Output is automatically recorded, eliminates the operator to register the work.

- The computerized systems automatically balance the work between stations.

- Up to 40 styles can be produced simultaneously on one system.

Weakness of unit production system:

- Unit production system requires high investments.

- The payback period of the investment takes long time.

- Proper planning is required to be effective. [15] 
Table 1. Comparison between PBS and UPS [16].

\begin{tabular}{|c|c|c|}
\hline Parameters & Progressive Bundle System (PBS) & Unit Production System (UPS) \\
\hline Transportation & $\begin{array}{l}\text {-Manual transportation, many times helper are hired for this bundle } \\
\text { transportation job. } \\
\text {-Operators stop their work to fetch bundles. } \\
\text {-Less effective in terms of production management. Resulted long } \\
\text { response time. }\end{array}$ & $\begin{array}{l}\text {-In this system an automated mechanical system } \\
\text { carries pieces to each work stations. } \\
\text {-Easier pick up and dispose at each work station. } \\
\text { Resulted quick response time }\end{array}$ \\
\hline Through put time & $\begin{array}{l}\text {-Compare to UPS, through put time longer in PBS. How much long } \\
\text { will depend on the bundle size and no. of bundles kept in between } \\
\text { two operators. }\end{array}$ & $\begin{array}{l}\text {-Through put time in UPS is less compare to PBS. } \\
\text { But it is not the minimum time as in this system } \\
\text { there is WIP in between two operators. } \\
\text {-Direct labor content is less than PBS because an }\end{array}$ \\
\hline Direct Labor content & $\begin{array}{l}\text { - Direct labor content is high because usually operator does tying and } \\
\text { untying of bundles, positioning components, pulling the bundle ticket } \\
\text { and handling of work pieces. }\end{array}$ & $\begin{array}{l}\text { operator only sews the garment part rather than } \\
\text { other tasks. In this system garment parts are held } \\
\text { by the over head hanger, so less handling of } \\
\text { garment components. }\end{array}$ \\
\hline WIP level & $\begin{array}{l}\text {-In PBS generally operators are asked to sew as much pieces as they } \\
\text { can without considering back and front operators. This resulted piling } \\
\text { up of work in the operations with higher work content. }\end{array}$ & $\begin{array}{l}\text {-Less WIP in between operators. As workstation } \\
\text { has limit of holding no. of hangers. Also after } \\
\text { completion of operation hangers are transported to } \\
\text { the next operation automatically. }\end{array}$ \\
\hline Cutting work requirement & $\begin{array}{l}\text {-As a result of High Work In Process (WIP) is required by sewing } \\
\text { section, cutting sections are required to perform } 60-70 \% \text { more than } \\
\text { actual production can handle. }\end{array}$ & $\begin{array}{l}\text {-Lower WIP results in less cutting works. A } \\
\text { balanced flow of material established in between } \\
\text { cutting and sewing line. }\end{array}$ \\
\hline Inventory Level & $\begin{array}{l}\text {-Due high WIP and higher cutting, fabrics and trims need to stock in } \\
\text { advance }\end{array}$ & -Less inventory for fabric and trims. \\
\hline Excess labor requirement & $\begin{array}{l}\text { - Usually in PBS needs more overtime works, repair work due to } \\
\text { some unfinished operations. }\end{array}$ & $\begin{array}{l}\text {-Plant with UPS system needs less overtime as } \\
\text { planning is easy in this manufacturing system. }\end{array}$ \\
\hline
\end{tabular}

Modular Manufacturing Systems (MDS)

A modular garments production system is a contained, manageable work unit that includes an empowered work team, equipment, and work to be executed. Modules frequently operate as minuscule factories with teams responsible for group goals and self-management. The number of teams in a plant varies with the size and needs of the firm and product line in garments. Teams can have a niche function as long as there are orders for that type of garments product, but the success of this type of garments operation is in the flexibility of being able to produce a wide variety of products in small quantities in garments.

Positive sides of modular manufacturing systems:

- High flexibility

- Fast throughput times

- Low wastages

- Improved Quality

Weakness of modular manufacturing systems:

- A high capital investment in equipment.

- High investment in initial training.

- High cost incurred in continued training [15]
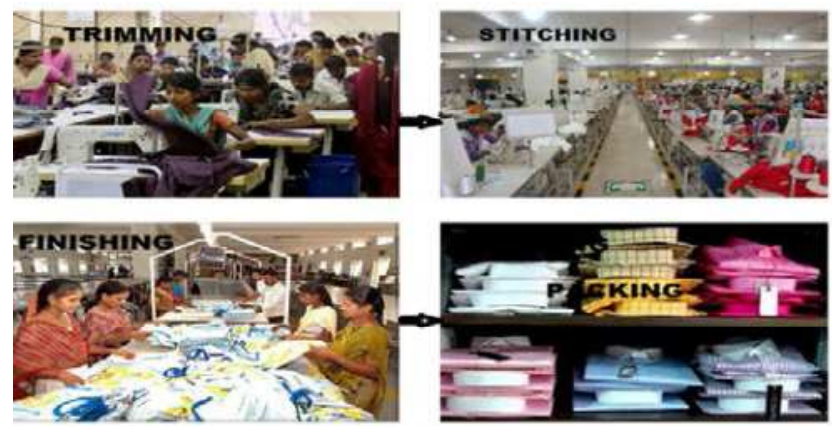

Figure 3. Modular Garments Production System. [14].
It seems that MPS is the perfect solution for the apparel manufacturer to respond to the quick replenishment requirement by the retailers. [17]. Although MPS can provide obvious benefits for the apparel manufactures, the diffusion of MPS in the apparel industry is slow. The possible reasons for this phenomenon are studied by the researchers, most from the perspective of human resource practices [18, 19].

Table 2. Predicted Attributes of the Three Commonly Adopted Production Systems [20].

\begin{tabular}{|c|c|c|c|}
\hline \multirow{2}{*}{$\begin{array}{l}\text { System } \\
\text { Attributes }\end{array}$} & \multicolumn{3}{|c|}{ Production Systems } \\
\hline & Bundle & $\begin{array}{l}\text { Progressive } \\
\text { Bundle }\end{array}$ & Modular \\
\hline Workflow & Push & Push & Pull \\
\hline $\begin{array}{l}\text { Method of } \\
\text { retrieval to } \\
\text { workstations }\end{array}$ & $\begin{array}{l}\text { Brought to } \\
\text { operator or } \\
\text { self-retrieved } \\
\text { from general } \\
\text { storage }\end{array}$ & $\begin{array}{l}\text { Brought to } \\
\text { operator from } \\
\text { operator by cart } \\
\text { or conveyor }\end{array}$ & Hand off \\
\hline $\begin{array}{l}\text { Work-in - } \\
\text { process(WPI) } \\
\text { inventory }\end{array}$ & $\begin{array}{l}\text { High levels } \\
\text { (racks or carts } \\
\text { of bundles) }\end{array}$ & $\begin{array}{l}\text { Moderate } \\
\text { (enough to } \\
\text { balance the } \\
\text { lines) }\end{array}$ & $\begin{array}{l}\text { Zero to } \\
\text { minimal }\end{array}$ \\
\hline $\begin{array}{l}\text { Number of task } \\
\text { per operator }\end{array}$ & $\begin{array}{l}\text { Single task or } \\
\text { whole garment }\end{array}$ & Single task & $\begin{array}{l}\text { Single to } \\
\text { multiple tasks }\end{array}$ \\
\hline $\begin{array}{l}\text { Interaction } \\
\text { between } \\
\text { operators }\end{array}$ & No teamwork & No teamwork & No teamwork \\
\hline
\end{tabular}

\section{Conclusion and Implications}

A vital thing is pointed out by manufacturing connoisseur and researchers that bewilderment subsist with the terminology concerning apparel production systems, and contemporary apparel literature does not afford industry- 
based and empirically scrutinized definitions for the three most widespread production systems (i.e., bundle, progression bundle and modular).

In Bangladesh primarily Progressive Bundle System (PBS) is used as 80 percent of the Exporting products are Knitted Products. For knitted products, all items bundle together. Example: Esquire Knit Composite, etc.

For woven garments, a group of item bundle tighter, Example: Ananta Apparels, etc.

But in some industries Unit Production System (UPS) is used. Example: Pacific Jeans.

Modular Manufacturing Systems implemented by all industries in sample section.

In a nutshell, it can be said that, all sorts of production systems are available in Bangladeshi apparel industry; nonetheless the use of Progressive Bundle System (PBS) is significantly higher than others.

\section{References}

[1] Ruth E. Glock, Grace I. Kunz. ; (2005), Apparel Manufacturing: Sewn Product Analysis (4th ed.), P. 345.

[2] Doeringer, P., \& Crean, S. (2006). Can fast fashion save the U.S. apparel industry? Socio-Economic Review, 4, 353-377.

[3] Monacarz, H.T. (1992), Information technology vision for the U.S. fibre/textile / apparel industry (NISTIR No. 4986). Gaithersburg, MD: U.S. Department of Commerce.

[4] Park, H., \& Kincade, D.H. (2011). A historic review of environmental factors and business strategies for U.S. apparel manufacturing industry, 1973-2005. Research Journal of Textile and Apparel, 15(4), 102-114.

[5] Anonymous (May 14, 2011). Moving back to America: Multinational manufacturers. The Economist.

[6] Friedman, A. (2012, September 5). Back in the U.S. they are WWD, Section II. Retrieved from http://www.wwd.com

[7] Kim, Y., \& Rucker, M. (2005). Production sourcing strategies in the U.S. apparel industry: A modified transaction cost approach. Clothing and Textile Research Journal, 23 (1), Pg.1-12.

[8] Su, J., Dyer, C.L., \& Gargeya, V.B. (2009), Strategic sourcing and supplier selection in the U.S. textile-apparel-retail supply network. Clothing and Textile Research Journal, 27 (2), Pg.83-91.

[9] G. Pan, (2014), A Quantitative Analysis of Cellular Manufacturing in Apparel Industry by Using Simulation, Journal of Industrial Engineering and Management, Vol :7 Iss: 5, Pg.1385-1396.

[10] H. Eberle, et al.; (2008), Clothing Technology: From fibre to fashion, (5th ed); Pg. 128.

[11] H. Eberle, et al.; (2008), Clothing Technology: From fibre to fashion, (5th ed); Pg. 128.

[12] Ruth E. Glock, Grace I. Kunz.; (2005) Apparel Manufacturing: Sewn Product Analysis (4th ed.), Pg. 346.

[13] The Indian Textile Journal (http://www.indiantextilejournal.com/articles/FAdetails.asp?id $=1988$ )

[14] B.Sudarshan, D. Nageswara Rao ; (2013) "Application of Modular manufacturing System in Garment Industries"; International Journal of Scientific \& Engineering Research; Vol 4 ; Is 12; Pg: 2083-2089.

[15] V. R. Babu; "Garment production systems: An overview"; The Indian Textile Journal.

[16] Online Clothing Industries (http://www.onlineclothingstudy.com/2011/02/comparisonbetween-progressive-bundle.html).

[17] X. Wang, CH. Chiu, and W. Guo (2014), "Improving the Performance of Modular Production in the Apparel Assembly: A Mathematical Programming Approach", Mathematical Problems in Engineering, Vol 2014, ID 472781, Pg.7 .

[18] J. T. Dunlop and D. Weil (1996), "Diffusion and performance of modular production in the U.S. apparel industry," Industrial Relations, vol 35, no 3, Pg. 334-355.

[19] P. Berg, E. Appelbaum, T. Bailey, and A. L. Kalleberg (1996), "The performance effects of modular production in the apparel industry," Industrial Relations, vol. 35, no. 3, Pg. 356-373, 1996.

[20] D. Kincade, J. Kim, \& k. Kanakadurga (2013). An empirical investigation of apparel production systems and product line groups through the use of collar designs. Journal of Textile and Apparel, Technology and Management, vol 8, iss 1, Pg. 115. 